\title{
Myotonic dystrophy type 1 as a major risk factor for severe COVID-19?
}

\author{
Sebastiaan Dhont ${ }^{1}$ (1) $\cdot$ Rutger Callens $^{1} \cdot$ Dieter Stevens $^{2} \cdot$ Fre Bauters $^{2} \cdot$ Jan L. De Bleecker ${ }^{3} \cdot$ Eric Derom $^{2}$. \\ Eva Van Braeckel ${ }^{2}$
}

Received: 7 August 2020 / Accepted: 28 September 2020 / Published online: 14 October 2020

(c) Belgian Neurological Society 2020

\begin{abstract}
The coronavirus disease 2019 (COVID-19) pandemic is challenging health care systems worldwide. People with myotonic dystrophy type 1 (DM1) represent a high-risk population during infectious disease outbreaks, little is known about the potential impact of COVID-19 on patients with DM1. We studied the clinical course of COVID-19 in three hospitalized patients with myotonic dystrophy type 1 or Steinert's disease, between April 1, 2020-April 30-2020. All three had advanced Steinert's disease receiving non-invasive nocturnal home ventilatory support. Two of them lived in a residential care centre. Two patients had a limited respiratory capacity, whereas one patient had a rather preserved functional capacity but more comorbidities. Two out of three patients were obese, none of them had diabetes mellitus. Two patients received hydroxychloroquine. Despite maximal supportive care with oxygen therapy, antibiotics, intensive respiratory physiotherapy and noninvasive positive pressure ventilation, all three patients eventually died due to COVID-19. Our case series of three patients with DM1 admitted for COVID-19 confirms that they are at high risk for severe disease and poor outcome. Clinical trials are needed to define best practices and determinants of outcomes in this unique population.
\end{abstract}

Keywords Steinert's disease $\cdot$ Myotonic dystrophy $\cdot$ Neuromuscular disorders $\cdot$ COVID-19 $\cdot$ SARS-CoV-2

\section{Abbreviations \\ COVID-19 Coronavirus disease 2019 \\ DM1 Myotonic dystrophy type 1 \\ PCR Polymerase chain reaction}

SARS-CoV-2 Severe acute respiratory syndrome coronavirus 2

NIPPV Non-invasive positive pressure ventilation

ARDS Acute respiratory distress syndrome

Sebastiaan Dhont

sebastiaan.dhont@ugent.be

1 Department of Internal Medicine and Paediatrics, Ghent University Hospital, Corneel Heymanslaan 10, 9000 Ghent, Belgium

2 Department of Respiratory Medicine, Ghent University Hospital, Ghent, Belgium

3 Neuromuscular Reference Centre, Ghent University Hospital, Ghent, Belgium

\section{Introduction}

Myotonic dystrophy type 1 (DM1) or Steinert's disease is an inherited neuromuscular disorder that primarily affects muscle function, characterized by progressive weakness and sustained muscle contraction $[1,2]$. Despite variable penetrance, DM is the most common type of adult muscular dystrophy, affecting at least one in 8000 people worldwide $[1,2]$. The genetic background is a variable expansion of an unstable nucleotide repeat located in the non-coding region of the respective gene (DMPK for DM1), causing mis-splicing of mRNAs which affects almost all cells and organs of the human body [2]. Nocturnal non-invasive positive pressure ventilatory support is often used to ensure breathing function. The development of an acute respiratory infection is associated with a temporary reduction in muscle strength and function [3]. Unlike in normal individuals, however, these decrements in respiratory muscle function may result in more severe illness and acute on chronic respiratory failure in patients with DM1 [4, 5]. Furthermore, DM1 is often accompanied by obesity, increased insulin resistance and cardiovascular disease; three major risk factors for severe COVID-19 [2, 6-8]. Avoidant personality disorder is common in DM1 which may lead to less strict adherence 
to medical advice such as social distancing. Herein, we describe the clinical course and outcomes of COVID-19 in three patients with DM1.

\section{Methods}

This observational study was approved by the institutional review boards of Ghent University Hospital (including the Neuromuscular Reference Centre) in Belgium. Diagnosis of COVID-19 was made on clinical history, epidemiological data, chest imaging and nasopharyngeal swab polymerase chain reaction (PCR) testing for severe acute respiratory syndrome coronavirus 2 (SARS-CoV-2). Based on the CT findings, the level of suspicion of COVID-19 infection is graded from very low or CO-RADS 1 up to very high or CO-RADS 5 [9]. All cases were admitted to the emergency department of Ghent University Hospital after referral of the general practitioner between April 1, 2020 and April 30, 2020.

\section{Results}

We describe three patients with DM1 admitted to the emergency department because of COVID-19. All three were patients of the multidisciplinary Neuromuscular Reference Centre of Ghent University Hospital and had genetically proven serious DM1 with advanced disease receiving noninvasive nocturnal home ventilatory support. Table 1 shows complete clinical and genetical information regarding each patient. Figures 1,2 and 3 show the radiologic findings on admission of each patient. Despite maximal supportive care with oxygen therapy, antibiotics, intensive respiratory physiotherapy and non-invasive positive pressure ventilation, all three patients eventually died on, respectively, day 6,5 and 8 of admission. We should remark that patient 1 had two negative nasopharyngeal swabs for SARS-CoV-2, a presumptive diagnosis of COVID-19 was made based on epidemiological, biochemical and radiographical grounds taking into account that the sensitivity for the nasopharyngeal swab

Table 1 Patient's characteristics

\begin{tabular}{|c|c|c|c|c|}
\hline & Patient 1 & Patient 2 & Patient 3 & \\
\hline Gender & $\mathrm{F}$ & $\mathrm{F}$ & M & \\
\hline Age & 44 & 47 & 64 & \\
\hline BMI & 37 & 33 & 23 & \\
\hline NIPPV & $\mathrm{Y}$, for 3 years & $\mathrm{Y}$, for 1 year & $\mathrm{Y}$, for 18 years & \\
\hline Weelchair-bound & $\mathrm{Y}$ & $\mathrm{N}$ & $\mathrm{N}$ & \\
\hline Residential care & $\mathrm{N}$ & $\mathrm{Y}$ & $\mathrm{Y}$ & \\
\hline Diabetes mellitus & $\mathrm{N}$ & $\mathrm{N}$ & $\mathrm{N}$ & \\
\hline Cardiovascular diseases & $\mathrm{N}$ & $\mathrm{N}$ & $\mathrm{Y}$ & \\
\hline Number of CTG-repeats & 700 & 300 & 150 & \\
\hline FVC (L) & 0.60 & 0.86 & 2.99 & \\
\hline$\%$ predicted & 16 & 24 & 68 & \\
\hline FEV1 (L) & 0.52 & 0.63 & 2.27 & \\
\hline$\%$ predicted & 17 & 22 & 68 & \\
\hline FEV1/FVC (\%) & 86 & 73 & 76 & \\
\hline White blood cells & 11.30 & 2.76 & 4.39 & $3.65-9.30103 / \mu \mathrm{L}$ \\
\hline Lymphocytes & 680 & 740 & 131 & $1133-3105 / \mu \mathrm{L}$ \\
\hline Platelets & 162 & 129 & 120 & $171-374103 / \mu \mathrm{L}$ \\
\hline CRP & 54.3 & 37.0 & 217.2 & $<5.0 \mathrm{mg} / \mathrm{L}$ \\
\hline Ferritin & 72 & 175 & 516 & $25-250 \mu \mathrm{g} / \mathrm{L}$ \\
\hline LDH & 496 & 335 & 514 & $105-250 \mathrm{U} / \mathrm{L}$ \\
\hline D-dimers & $<270$ & 810 & 1950 & $0-500 \mathrm{ng} / \mathrm{mL}$ \\
\hline Goals-of-care & No reanimation, no intubation & Best supportive care & No reanimation, no intubation & \\
\hline Therapy & $\begin{array}{l}\text { Hydroxychloroquine, non- } \\
\text { invasive ventilation, empiric } \\
\text { antimicrobial therapy and } \\
\text { intensive respiratory physi- } \\
\text { otherapy }\end{array}$ & $\begin{array}{l}\text { Hydroxychloroquine, non- } \\
\text { invasive ventilation, empiric } \\
\text { antimicrobial therapy and } \\
\text { intensive respiratory physi- } \\
\text { otherapy }\end{array}$ & $\begin{array}{l}\text { Non-invasive ventilation, } \\
\text { empiric antimicrobial therapy } \\
\text { and intensive respiratory } \\
\text { physiotherapy }\end{array}$ & \\
\hline Outcome & Died, 6th day & Died, 5th day & Died, 8th day & \\
\hline
\end{tabular}

$F$ female; $M$ male, $Y$ yes; $N$ no; $N I P P V$ non-invasive positive pressure ventilation; $N F$ nasopharygeal swab; $N$ negative; $Y$ positive 
Fig. 1 Chest CT of patient 1 showing bilateral patchy infiltrates, CO-RADS 4
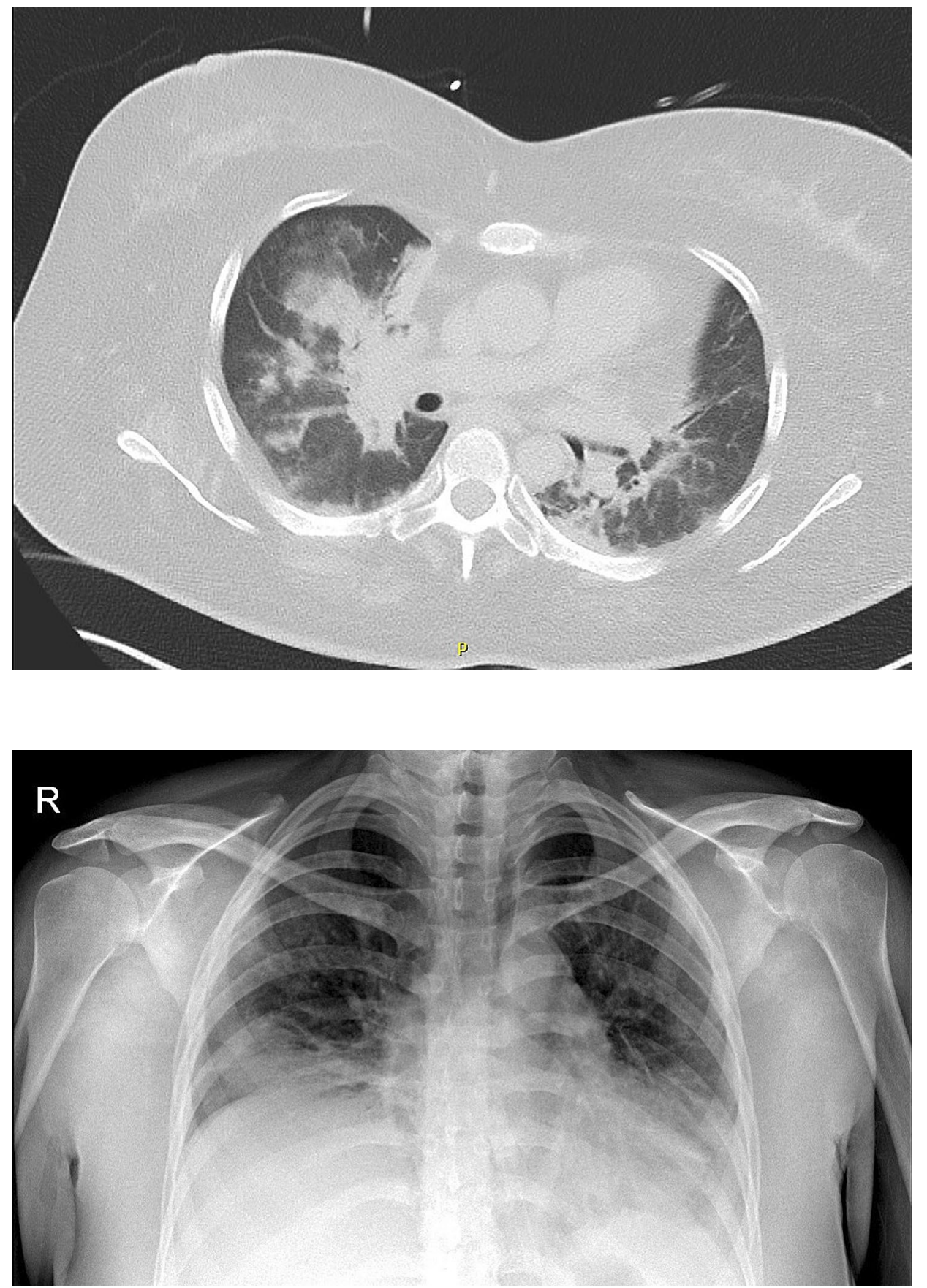

Fig. 2 Chest X-ray of patient 2 revealing bilateral infiltrates is around $70 \%$ [9]. Considering her precarious respiratory state, no bronchoalveolar lavage or repeat testing was performed. The CO-RADS score of 5 has a very high positive predictive value, especially in combination with the typical biochemical markers, given the high a priori-chance in this epidemic. In a high-prevalence emergency department setting, chest CT showed high probability of COVID-19 (CO-RADS 4-5) in $29.9 \%$ of patients with a negative or indeterminate initial RT-PCR result [9].

\section{Discussion}

Beside the risk factors highlighted in the introduction, such as respiratory muscle weakness, obesity and cardiovascular disorders, patients with DM1 could also be more prone to the hyperinflammation which is so typical for the acute respiratory distress syndrome (ARDS) in COVID-19. On a molecular basis, DM1 is characterized by trinucleotide repeat expansion in the $3^{\prime}$-untranslated region of the $D M P K$ gene. 
Fig. 3 Chest CT of patient 3 revealing bilateral opacities, CO-RADS 5

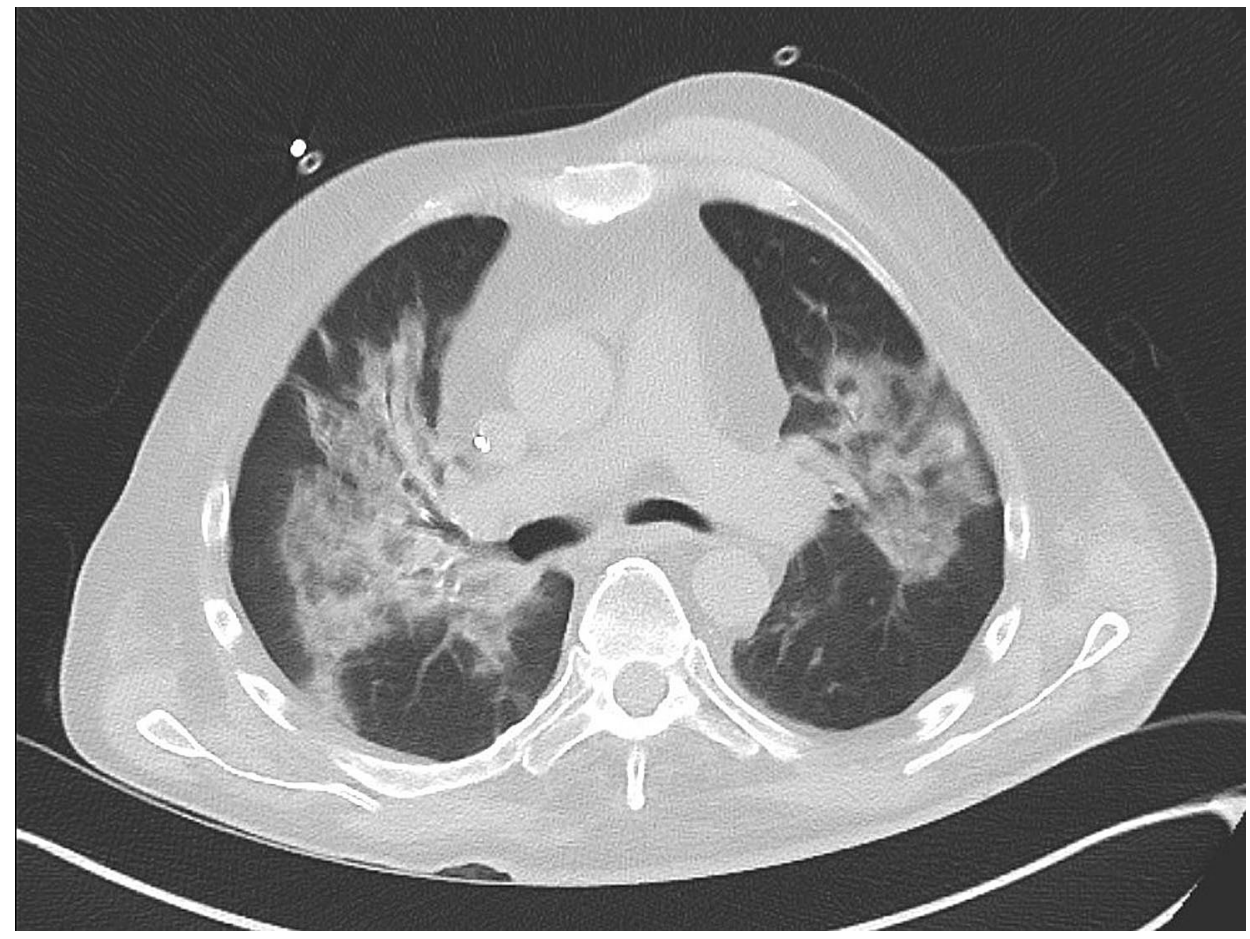

The mutant RNA-transcript with expanded CUG repeats, is assumed to serve as a trigger for interferon response, and elevated levels of the pro-inflammatory cytokines TNF$\alpha$, IL-6, and IL-1 $\beta$ cytokines were demonstrated in DM1 patients $[10,11]$. Many of these cytokines are known to be elevated during the hyperinflammatory syndrome and fulminant hypercytokinaemia (so-called cytokine storm) of severe COVID-19 [12]. It remains to be investigated whether this association does indeed lead to a more severe disease course in patients with DM1. Although inflammation is not an initiating factor in DM1, growing evidence indicates that inflammatory responses involving astrocytes, microglia, and the peripheral immune system may contribute to disease progression [3].

In Steinert's disease, progressive muscles weakness ultimately leads to respiratory failure, which is often managed using nocturnal home ventilatory support. There is a widespread concern that the use of non-invasive ventilation could increase the risk of viral transmission in COVID-19. This statement is based on theoretical concepts rather than clinical data. We believe that a coughing patient, with effective peak cough flows exceeding 460-400 L/min, is probably more contagious than a patient on non-invasive ventilation with a well-fitted mask interface covering nose and mouth [13-15]. An analysis of 75,465 COVID-19 cases in China did not report airborne transmission [16]. This is why, in our hospital, we have the policy to continue NIPPV in patients with DM1 with their home ventilator with a well-fitted interface. The patients were admitted into individual negativepressure rooms with airborne and contact precautions.
Several candidate therapies have been tested in DM1 models, but none have reached clinical practice yet. Bargiela et al. suggested chloroquine as a possible strategy based on the finding that chloroquine treatment is able to upregulate musclebind levels in in vitro and in vivo models [17]. At the beginning of the COVID-19 pandemic, (hydroxy)chloroquine was proposed as one of the most promising drugs due to its anti-viral and immunosuppressive properties. However, this hypothesis has become highly controversial with an overall weak evidentiary basis [18]. As mentioned, hydroxychloroquine was initiated in two out of three cases without apparent improvement, although randomized trials are needed to confirm our findings. Moreover, hydroxychloroquine can trigger a flare-up in several neuromuscular disorders and can cause chloroquine myopathy [19-21].

Lastly, COVID-19 is overwhelming health care systems worldwide, putting pressure on infrastructure and staff and thereby provoking ethical issues [6]. Patients with DM1 who have a great burden of chronic illness often have limited prognosis in the ICU and may find their quality of life after prolonged life support unacceptable [22]. Therefore, advanced care planning and discussions of goals-of-care prior to the occurrence of serious acute illness should be given priority. This may prevent emotional distress in unprepared patients or their families upon admission since the psychological impact of COVID-19 on hospitalized patients and their relatives cannot be overestimated. Baseline lung function values of patients with neuromuscular disorders may be used as important prognostic values. As our third patient still had an FEV1 of $2.3 \mathrm{~L}$ without a more favourable 
disease course, the respiratory function alone may not be sufficient for risk stratification. Beside the severity of DM1, comorbidities such as obesity, cardiovascular and renal involvement may be of particular significance, although the relative importance remains unclear [23]

\section{Conclusion}

Based upon the severe disease course of these three cases, the primary advice for all patients with DM1 and their caregivers is to maximally reduce the risk of contracting the SARS-CoV-2 through e.g. social distancing, handwashing, and stricter isolation. Once infected, patients with DM1 should be closely monitored, as they seem to be at higher risk for severe COVID-19.

Author contributions SD and RC wrote the manuscript. DS, FB, JDB, ED and EVB read and corrected were needed. All authors took part in the discussion leading up to the manuscript.

\section{Compliance with ethical standards}

Conflict of interest The authors declare no competing financial interests.

Ethical approval All procedures performed in studies involving human participants were in accordance with the ethical standards of the institutional and national research committee and with the 1964 Helsinki declaration and its later amendments. The Ethic Committee of University of Ghent has approved our manuscript to ensure that they agree with local and international ethical guidelines.

\section{References}

1. Buxton J, Shelbourne P, Davies J et al (1992) Detection of an unstable fragment of DNA specific to individuals with myotonic dystrophy. Nature 355:547-548. https://doi.org/10.1038/355547a0

2. Wenninger S, Montagnese F, Schoser B (2018) Core clinical phenotypes in Myotonic Dystrophies. Front. Neurol. 9:303. https:// doi.org/10.3389/fneur.2018.00303

3. Poponick JM, Jacobs I, Supinski G, Dimarco AF (1997) Effect of upper respiratory tract infection in patients with neuromuscular disease. Am J Respir Crit Care Med 156:659-664. https://doi. org/10.1164/ajrccm.156.2.9611029

4. Reardon W, Newcombe R, Fenton I et al (1993) The natural history of congenital myotonic dystrophy: mortality and long term clinical aspects. Arch Dis Child 68:177-181. https://doi. org/10.1136/adc.68.2.177

5. Mier-Jedrzejowicz A, Brophy C, Green M (1988) Respiratory muscle weakness during upper respiratory tract infections. Am Rev Respir Dis 138:5-7. https://doi.org/10.1164/ajrccm/138.1.5

6. Berlin DA, Gulick RM, Martinez FJ (2020) Severe Covid-19. N Engl J Med. https://doi.org/10.1056/NEJMcp2009575
7. Peric S, Bozovic I, Nisic T et al (2019) Body composition analysis in patients with myotonic dystrophy types 1 and 2. Neurol Sci 40:1035-1040. https://doi.org/10.1007/s10072-019-03763-0

8. Vujnic M, Peric S, Calic Z et al (2018) Metabolic Impairments in Patients With Myotonic Dystrophy Type 2. Acta Myol myopathies cardiomyopathies Off J Mediterr Soc Myol 37(4):252-256

9. Prokop M, van Everdingen W, van Rees VT et al (2020) CORADS - A categorical CT assessment scheme for patients with suspected COVID-19: definition and evaluation. Radiology. https ://doi.org/10.1148/radiol.2020201473

10. Olejniczak M, Urbanek MO, Krzyzosiak WJ (2015) The role of the immune system in triplet repeat expansion diseases. Mediators Inflamm 2015:873860. https://doi.org/10.1155/2015/873860

11. Rhodes JD, Lott MC, Russell SL et al (2012) Activation of the innate immune response and interferon signalling in myotonic dystrophy type 1 and type 2 cataracts. Hum Mol Genet 21:852862. https://doi.org/10.1093/hmg/ddr515

12. Mehta P, McAuley DF, Brown M, et al (2020) COVID-19: consider cytokine storm syndromes and immunosuppression. https:// doi.org/10.1016/S0140-6736(20)30628-0

13. Mellies U, Goebel C (2014) Optimum insufflation capacity and peak cough flow in neuromuscular disorders. Ann Am Thorac Soc 11:1560-1568. https://doi.org/10.1513/AnnalsATS.20140 6-264OC

14. Leiner GC, Abramowitz S, Small MJ et al (1963) Expiratory peak flow rate. Standard values for normal subjects. Use as a clinical test of ventilatory function. Am Rev Respir dis 88:644-651. https ://doi.org/10.1164/arrd.1963.88.5.644

15. Gregg I, Nunn AJ (1973) Peak expiratory flow in normal subjects. Br Med J 3:282-284. https://doi.org/10.1136/bmj.3.5874.282

16. (2020) Modes of transmission of virus causing COVID-19: implications for IPC precaution recommendations. https://doi. org/10.3201/eid2606.200239

17. Bargiela A, Sabater-Arcis M, Espinosa-Espinosa J et al (2019) Increased Muscleblind levels by chloroquine treatment improve myotonic dystrophy type 1 phenotypes in in vitro and in vivo models. Proc Natl Acad Sci U S A 116:25203-25213. https://doi. org/10.1073/pnas.1820297116

18. Geleris J, Sun Y, Platt J et al (2020) Observational study of hydroxychloroquine in hospitalized patients with Covid-19. N Engl J Med. https://doi.org/10.1056/NEJMoa2012410

19. Lindquist $S$, Stangel M (2011) Update on treatment options for Lambert-Eaton myasthenic syndrome: focus on use of amifampridine. Neuropsychiatr Dis Treat 7:341-349

20. Varan O, Kucuk H, Tufan A (2015) Myasthenia gravis due to hydroxychloroquine. Reumatismo 67:125

21. Wasay M, Wolfe GI, Herrold JM et al (1998) Chloroquine myopathy and neuropathy with elevated CSF protein. Neurology 51:1226-1227

22. Curtis JR, Kross EK, Stapleton RD (2020) The importance of addressing advance care planning and decisions about do-notresuscitate orders during novel coronavirus 2019 (COVID-19). JAMA 323:1771-1772

23. Jordan RE, Adab P, Cheng KK (2020) Covid-19: risk factors for severe disease and death. BMJ. https://doi.org/10.1136/bmj. m1198

Publisher's Note Springer Nature remains neutral with regard to jurisdictional claims in published maps and institutional affiliations. 